\title{
Giant Freshwater Prawn Macrobrachium rosenbergii Farming: A Review on its Current Status and Prospective in Malaysia
}

\author{
Rubia Banu ${ }^{1 *}$ and Annie Christianus ${ }^{1,2}$ \\ ${ }^{1}$ Department of Aquaculture, Faculty of Agriculture, University Putra Malaysia, Serdang, Selangor, Malaysia \\ ${ }^{2}$ Institute of Biosciences, Universiti Putra Malaysia, Serdang, Selangor, Malaysia
}

\begin{abstract}
In Malaysia, the giant freshwater prawn Macrobrachium rosenbergii is becoming an increasingly important targeted species, as its culture, is considered to have the potential to raise income among impoverished farmers. Although, total freshwater aquaculture production decreased in the year 2013 compared to previous year, the aquaculture production of $M$. rosenbergii increased from 318 tonnes in 2012 to 457 tonnes in 2013 . Recently, the production of giant freshwater fries increased from the three government and 21 private hatcheries in 2012 to the four government and 19 private hatcheries in 2013. The number and production of feed mills increased in 2013 compared to the four years ago. Until recently, lack of a stable nursery of PL and feed had been an important obstacle to the further expansion and development of $M$. rosenbergii culture. This paper reviews the current status of freshwater prawn culture in Malaysia and background history, and future prospects of freshwater prawn farming. It was concluded that freshwater prawn farming in Malaysia has a favorable scenario for expansion due to increasing demand and to prospects of an improved organization of the productive chain.
\end{abstract}

Keywords: Giant freshwater prawn; Macrobrachium rosenbergii; Malaysia; Status

\section{Introduction}

The giant freshwater prawn, Macrobrachium rosenbergii (de Man), locally known as udang galah, is distributing from north-west India to Vietnam, Philippines, Papua New Guinea and Northern Australia [1]. It is the biggest freshwater prawn in the world, the male growing size of $320 \mathrm{~mm}$ and weighing over $200 \mathrm{~g}$ [2]. The expert of the Food and Agriculture Organization (FAO) as Shao-Wen Ling who discovered that the survival of the giant freshwater prawn (Macrobrachium rosenbergii) larvae was possible in brackish environment. This achievement was at Marine Fisheries Research Institute in Penang, Malaysia in 1961. In 1965, Takuji Fujimura commenced his research in Hawaii, with the introduction of freshwater prawn (M. rosenbergii) broodstock from Malaysia and developed the commercial culture of freshwater prawn [3]. The World Aquaculture Society had granted honorary to these two as life membership of the Society as well as called them 'Fathers' of freshwater prawn farming in 1974 (Shao-Wen Ling) and 1979 (Takuji Fujimura) for their work.

Aquaculture plays a pivotal role within the NKEA (National Key Economic Area), which is at the core of the Malaysian Government's Economic Transformation Programme (ETP). The programme serves to stimulate economic activity towards attaining high income, sustainability and inclusiveness for the nation. With global demand for aquaculture products expected to increase above 635 million tonnes in 2020 from the present 251 million tonnes, potential for growth is excellent. The aquaculture production was at 194,139 tonnes (USD 308 million) in 2003 contributing approximately $20 \%$ of the total value of the aquaculture production in Malaysia. Aquaculture has become an important way of increasing local yield for food security and to increase export revenues in Malaysia. While aquaculture currently contributes less than 0.2 percent to the gross domestic production (GDP), the fact that it accounts for no less than $20 \%$ of the overall fisheries production in Malaysia, a proportion that will only grow larger in the future, is testimony to its considerable importance.

The Department of Fisheries [4] has set its target on four entry point projects (EPP), namely, an integrated cage aquaculture project, a mini estate in seaweed production, seed industry development and replication of Integrated Zone for Aquaculture-IZAQ. These 4 EPP's are predicted to provide 35,100 jobs. The investment of private sector will total MYR 2.57 billion whilst the input of the public sector will be 346.25 million. The aquaculture production target will encompass food commodities (giant freshwater prawn, marine shrimp, marine finfish and mollusc) with total up to 507,558 tonnes and values of MYR 6,325 million. With the zoning of aquaculture area (AIZ) projected aquaculture production will reach 730,000 metric tonnes with a value of MYR 7 billion in 2016.

Giant freshwater prawn, $M$. rosenbergii is among the commercial aquaculture species being given high priority by Department of Fisheries, Malaysia [5] as food and food products for consumption and export. It is also being emphasised by this research group due to more and continuous development needed in various aspects of this giant freshwater prawn industry. The output of farmed giant freshwater prawn (M. rosenbergii) which was less than 3,000 tonnes 30 years ago expanded tremendously and had risen to almost 420,000 tonnes, with a value of USD 2.13 billion in 2008. Farmed production of $M$. rosenbergii constituted over $51 \%$ of the global total. However, production trends for cultured giant freshwater prawn in Malaysia fell 218\% from 627 million tonnes in 2003 to 197 million tonnes in 2006 while in parallel rapidly expanding in Asia particularly in China, India and Thailand, though Malaysia pioneered the breeding of this species in the late 50's. The fall in its production as compared with other freshwater species like tilapia and catfish (keli) among others was due to declining supply

*Corresponding author: Rubia Banu, Department of Aquaculture, Faculty of Agriculture, University Putra Malaysia, Serdang, Selangor, Malaysia, Tel: +60123391078, +603-8947 4884; Fax: +603-8940 8311; E-mail: rubiaprodhan@gmail.com

Received March 31, 2016; Accepted April 22, 2016; Published April 25, 2016

Citation: Banu R, Christianus A (2016) Giant Freshwater Prawn Macrobrachium rosenbergii Farming: A Review on its Current Status and Prospective in Malaysia. J Aquac Res Development. 7: 423. doi:10.4172/2155-9546.1000423

Copyright: $\odot 2016$ Banu R, et al. This is an open-access article distributed under the terms of the Creative Commons Attribution License, which permits unrestricted use, distribution, and reproduction in any medium, provided the original author and source are credited. 
of quality broodstock, low productivity, low culture technology and a high dependence on imported food for larval stages [6].

Therefore, to successfully compete, Malaysia must invest in research areas that will help to intensify and sustain the production of farmed giant freshwater prawn so that it is environmentally nondegrading, economically viable and socially acceptable. Recent report by DOF (2011) [6] revealed that Malaysia has achieved 100\% selfsufficiency in fish production (mainly contributed by capture fisheries and culture of high valued marine species). Moreover, the MYR 2.4 billion contributed by balanced values for import and export from Malaysian aquaculture production showed that there is a need to increase freshwater culture production particularly for giant freshwater prawn. An increase in cultured freshwater prawn, $M$. rosenbergii, not only will likely improve livelihoods, but also provides a cheap source of protein and will towards to increase export revenues for the Malaysian economy.

According to FAO data on M. rosenbergii [7], it reports that the production of $M$. rosenbergii in 2007 was over $99 \%$ of global farmed production in Asia, while the other major producing regions are South America and Central America. The five major producing countries of Asia are China (56.3\% of 2007 global production), Thailand (12.5\%), India (12.3\%), Bangladesh $11 \%$ and Taiwan (4.5\%). According to the FAO data, the production of only three other countries exceeded 200 $\mathrm{t}$ of production in 2007: Iran (258 t), Malaysia (246 t) and Brazil (230 t). Now the trend has changed in the last decades. Though marine capture fisheries constitute $86.9 \%$ of Malaysia's fish production, coastal fisheries remain a major contributor. However, production from deep sea fisheries sector in the Exclusive Economic Zone (EEZ) is still expanding [8].

According to the Food and Agriculture Organization [7], the world fish harvested in 2008 consisted 88.9 million tonnes captured by commercial fishing in wild fisheries, plus 55.9 million tonnes by fish farms. In addition, 14.8 million tonnes were produced from aquaculture. Overfishing and pollution are destroying the ocean ecosystem at an accelerating pace and of concern the world's fish and seafood could disappear by 2048 [7]. Thus, aquaculture is an alternative, the average contribution of aquaculture to per capita fish available for human consumption increased from $14 \%$ in 1986, $30 \%$ in 1996 and to $47 \%$ in 2006 , and is expected to reach $50 \%$ in the next few years [9].

\section{Production of the Giant Freshwater Prawn in Malaysia}

The first recognized output of farmed giant river prawn $(M$. rosenbergii) production recorded in FAO statistics appeared in 1970 [9]. Global production of the prawn in 2009 was 229,419 tones, of which 552 tones came from Malaysia [10]. Malaysia has a high potential for aquaculture development due to the country's favorable conditions in terms of natural habitats such as ponds, rivers, lakes, estuaries, and coastal areas. Since the beginning of the 2000s, the aquaculture sector in Malaysia has been expanding in terms of culture area, production, targeted species and degree of management intensity. Production based on aquaculture has been increasing rapidly in comparison with that from capture fisheries, particularly recently (Figure 1). Recently, some species, and certain culture system types, have contributed significantly to the growth of the aquaculture sector in terms of production and export values.

Freshwater prawn farming has a special significance for Malaysia, where Shao- Wen Ling's pioneer studies were made. Interest was strong in the late 1970s and the 1980s, when developments included the establishment of 2 government hatcheries and a 40 ha farm in Selangor. However, the volume of production from commercial farming has been relatively modest and extremely variable. A decade ago, production was expected to increase [11], judged by the increased demand for PL and juveniles and the number of new and expanded farms. The high prices achieved for prawns were reported to be turning the attention of farmers away from finfish.

In 1999, a large (1200 ha) eel farm in Pahang that had been facing difficulties in obtaining sufficient levers was reported to have made a decision to convert some of its ponds to freshwater prawn culture. Other favorable factors included the more ready availability of commercial aquafeeds in Malaysia, together with increasing support from government, university and private sectors (national farmers associations). In fact, national production did markedly increase, more than doubling from $281 \mathrm{t}$ in 1998 to $653 \mathrm{t}$ in 1999 and doubling again to $1338 \mathrm{t}$ in 2000 . However, between 2001 and 2005, average output was less than half the peak level and very variable (average $549 \mathrm{t} / \mathrm{yr}$; range 317 to $752 \mathrm{t} / \mathrm{yr}$ ). FAO data show that production fell markedly to only $194 \mathrm{t}$ in 2006 but had increased until $619 \mathrm{t}$ in 2010 . However, the latest official data showed a production of $457 \mathrm{t}$ in 2013 risen compared to 318 tons in last year. The production of $M$. rossenbergii in last decade showed in Figure 2.

Although, the global production of $M$. rosenbergii in 2007 was over $221000 \mathrm{t}, 2.7$ times greater than a decade earlier, the production in Malaysia has decreased almost half in 2011compared to 2010. The limiting factor is said to be the supply of quality juveniles. In addition, many causes contribute to decrease the production of $M$. rosenbergii in Malaysia tremendously for the last decade. Although, the production

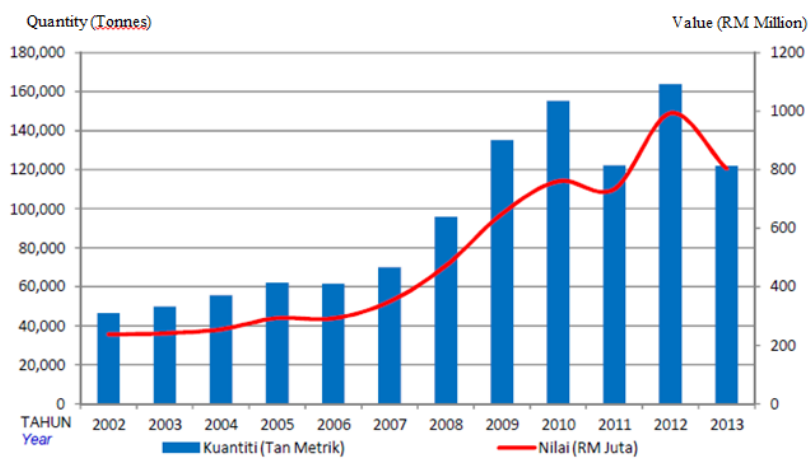

Figure 1: The production and value of freshwater fish from all freshwater aquaculture system in Malaysia (Anon, 2014).

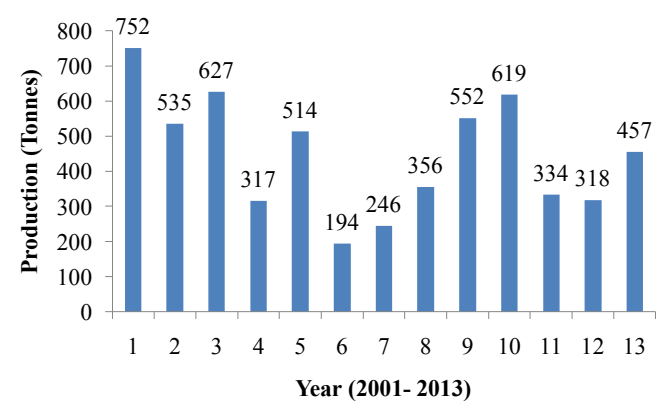

Figure 2: The production of giant freshwater prawn in Malaysia. (Source: New, 2010; Anon, 2008-2014). 
of freshwater aquaculture system has decreased in 2013 compared to 2012, the production of freshwater prawn has increased again in 2013 compared to 2012.

\section{Brood Stock and PL Production in Hatchery}

Early project work was carried out at Tanjung Demong Hatchery, which was under the responsibility of the Department of Fisheries [12]. The hatchery started functioning in January 1984. Facilities were installed such as, nursing tanks, pipes for freshwater and sea water, aeration, cements tanks, etc. Before commencing hatchery operations, the staffing structure was planned and individual duties specified. As the equipment was unfamiliar to the staff, instructions were given regarding its use. About 60 giant freshwater prawn breeders were collected from the Sabak Hatchery in January 1984. During January-February 1984, during production of freshwater prawn fry at Tanjung Demong Hatchery, about 100000 fry was produced. By the '70s, the Fisheries Research Institute had designed and built medium-scale hatcheries both Gelugor and at other locations (Perak, Negeri Sembilan, Kelantan, Kedah) to increase juvenile production to meet growing demands. These ventures however, did not meet with commercial success [13].

Subsequently, during the 1980's, the Fisheries Department was able to make a big leap forward, which enabled the hatchery center at Kampong Pulau Sayak, Kedah to be first upgraded in 1985 and then considerably expanded in 1987, to become the National Prawn Fry Production and Research Centre (NAPFRE). Prawn fry production made quantum leap and was able to meet the requirements of prawn farmers, with surplus seed stock for semi-intensive pond grow-out trials as well as restocking of natural water bodies [13].

Eighty per cent of the brood stock used by Malaysian hatcheries was reported to come from rivers in 1999, while the rest were the largest healthiest berried females selected from grow-out ponds. In 2007, however, it was reported that although brood stock from rivers are still preferred and the majority still come from that source, the supply is limited so they are also increasingly obtained from grow-out ponds. There has also been some import of brood stock from Thailand to enhance reproductive performance, together with some genetic selection. Unlike the practice in most producing countries, many Malaysian freshwater prawn hatcheries operate a green water System with minimal water exchange; only a few operate a clear water system. Most hatcheries are located coastally but some truck seawater $100 \mathrm{~km}$ to inland sites.

Larvae are stocked at 20 to 60/L and probiotics are sometimes used in the hatcheries, which typically achieve $50 \%$ survival. Larvae are fed Artemia nauplii, Artemia flakes, egg custards and commercial feeds. Chlorine and formalin are utilized in hatcheries, but no antibiotics. According to one correspondent, the use of the static green water technique has resulted in low and erratic PL production. Another correspondent reported that problems have been experienced with the survival of PL, shortly after metamorphosis, from both green water and clear water systems, but the cause has not yet been identified. In 2006, official statistics indicated that there were 3 government and 18 private hatcheries offering freshwater prawn PL. In 2007 a correspondent reported that there were more than 30 mostly small Malaysian freshwater prawn hatcheries, with a typical capacity of 200 $000 \mathrm{PL} /$ cycle, but they were unable to satisfy demand. Recently, the production of giant freshwater fries (Table 1) increased from the three government and 21 private hatcheries in 2012 to the four government and 19 private hatcheries in 2013 (Table 2).

\begin{tabular}{|c|c|c|}
\hline Year & $\begin{array}{c}\text { Government Hatchery } \\
\text { (Million pieces) }\end{array}$ & $\begin{array}{c}\text { Private Hatchery } \\
\text { (Million pieces) }\end{array}$ \\
\hline 2008 & 697.38 & 16.69 \\
\hline 2009 & 311.65 & 159.75 \\
\hline 2010 & 698.66 & 38.01 \\
\hline 2011 & 638.52 & 40.53 \\
\hline 2012 & 783.2 & 31.00 \\
\hline 2013 & 563.58 & 69.08 \\
\hline
\end{tabular}

Table 1: The production of fry of freshwater prawn in hatchery in last few years.

\begin{tabular}{|c|c|c|c|}
\hline State & Government Hatchery & Private Hatchery & Total \\
\hline Kedah & PPPBUK Kg. Pulau Sayak & 1 & 2 \\
\hline Perak & PPUG Kg. Acheh & 13 & 14 \\
\hline Pulau Pinang & - & 3 & 3 \\
\hline Sarawak & Jabatan Pertanian Sarawak & - & 1 \\
\hline Sabah & - & 2 & 2 \\
\hline Terengganu & PPPIL Tg. Demong & - & 1 \\
\hline Total & & & $\mathbf{2 3}$ \\
\hline
\end{tabular}

Table 2: Giant freshwater prawn fry produced Hatchery in 2013, Malaysia (Anon 2014).

\section{Nursery of PL}

The role of government hatcheries in the production of giant freshwater prawn seed was also very critical. In 2008, there were 3 government hatcheries with a capacity of 697 million giant freshwater prawn juveniles. Juvenile's production in 2013 however, had reduced slightly to 564 million. Private sector investment in the field was small. In the same year, there were 19 commercial hatcheries, 13 in Perak, three in Pinang, one in Kedah and the other in Sabah, only succeeded in producing 69 million juveniles. The limited private sector investment in giant freshwater prawn hatcheries is reflective of a small grow-out base. There are no specialist nurseries. Some farmers use tanks and others use nursery ponds of 0.08 to 0.1 ha for stocking PL8-12 at 120 to $150 / \mathrm{m}^{2}$ (sometimes as high as $600 / \mathrm{m}^{2}$ ) for a period of 2 to 6 weeks. Sometimes hapas (net cages), stocked at 450 to $1000 \mathrm{PL} / \mathrm{m}^{2}$ and situated within grow-out ponds, are used instead of dedicated nursery ponds.

Grow-out farms are mostly small (ranging from $0.1-10$ ha but $\sim 75 \%<2$ ha) and obtain all their stock from hatcheries. About $50 \%$ of the hatcheries were owned by grow-out farmers in 1999 and sold $20 \%$ of their juveniles to others. Some 70 to $80 \%$ of the PL stocked by farmers came from local hatcheries and 5 to $20 \%$ from hatcheries located in other parts of Malaysia. Currently farmers prefer the better quality PL available from government hatcheries but there is a shortage so they source them where they can find them available, at a cost of US\$1319/1000. This makes exports of PL very attractive for Thai hatcheries, which can produce them much more cheaply. A considerable quantity of PL is imported from Thailand (estimates vary from $5-30 \%$ of the total Malaysian demand) but some farmers report that the survival and growth rate of those imported is poor (but this may relate to inadequate transport and stocking procedures).

\section{Water shortages and Grow-Out}

A major technical problem is seasonal water shortages in some areas. Between cycles, grow-out ponds are scraped, limed, fertilized, and tea seed cake is applied. Ponds are typically stocked with PL at 10 to $15 \mathrm{~m}^{-2}$. When juveniles are used they are graded and stocked into grow-out ponds at 10 to $18 \mathrm{~m}^{-2}$. All current production occurs in ponds, although there has been some experimental culture in canals in the past. There have also been some trials to produce all-male prawns 
for grow-out. Ponds are typically less than 0.2 ha; their shape is mainly rectangular (98\%), while the rest are irregular in shape. Urea (90-120 $\mathrm{kg} / \mathrm{ha})$, TSP (10-40 kg/ha) and processed chicken manure (100-200 kg/ ha) are commonly used as fertilizers.

\section{Feed}

Some farms use simple semi-moist farm-made feeds incorporating tapioca, copra, chicken viscera, soy sauce byproduct, rice bran, broken rice and other ingredients, while most use commercial freshwater prawn feeds that are available at US\$770/t (2008) and achieve an FCR of 1.8 to $3.0: 1$ [14]. However, some farmers pay nearly US\$ 1100 $1400 / t$ for marine shrimp feeds, believing that they get better grow-out production. The number and production of feed mills has increased from $27,78248.41 \mathrm{t}$ respectively in 2009 to $33,216806 \mathrm{t}$ respectively in 2013 (Table 3).

\section{Integration Culture}

Inadequate supply of juveniles and the encroachment of other developments that affect water quality are reported to have been problems. Some developmental work to encourage the integration of prawn culture with rice production was reported to be on-going in 1999. New (2010) [11] reported that the production was from 0.90 to $3.15 \mathrm{t} / \mathrm{ha} / \mathrm{crop}$ in Malaysia. By 2007 the productivity of some grow- out ponds was reported to range from $3.0 \mathrm{t} / \mathrm{ha}$ to as high as $6.5 \mathrm{t} / \mathrm{ha}$ per cycle. However, such high levels are only attainable for four or five consecutive cycles, after which growth rates are lower and production much less.

\section{General Discussion and Future Prospects}

Several reasons have been given for the inconsistent output of Malaysian freshwater prawn production. Most of the farms are family owned. During the first few cycles, production was good but slow growth and low production was encountered after the ponds had been stocked for more than five cycles. The operators then ceased operation because of low profitability. These poor results affected the yearly production figures. Those that had knowledge about the value of crop rotation then started to rear fish instead for one or two cycles, after which prawn productivity was found to improve again. The continued shortage of PL and their intermittent supply caused some farms to stock several species of available freshwater fish fry instead of prawns.

About $80 \%$ of the live adult prawns produced by these farms are sold to city leisure fishing pond operators and to restaurants. However, once prawn PL supply faltered the supply of adults was affected and the fishing pond operators were forced to stock fish instead and the restaurants owners were forced to delete freshwater prawns from their menus. When farms had prawns available their supply to fishing

\begin{tabular}{|c|c|c|c|c|}
\hline \multirow{2}{*}{ State } & \multicolumn{2}{|c|}{$\mathbf{2 0 0 9}$} & \multicolumn{2}{|c|}{$\mathbf{2 0 1 3}$} \\
\cline { 2 - 5 } & Number & $\begin{array}{c}\text { Production } \\
\text { (Tonnes) }\end{array}$ & Number & $\begin{array}{c}\text { Production } \\
\text { (Tonnes) }\end{array}$ \\
\hline Kedah & 3 & 3700.00 & 3 & 3026.00 \\
\hline Perak & 5 & 31000.00 & 8 & $176,095.00$ \\
\hline Selangor & 1 & 4860.00 & - & - \\
\hline Melaka & 1 & 7000.00 & 1 & 7680.00 \\
\hline Johor & 2 & 5292.16 & 9 & 29.00 \\
\hline Pahang & 1 & 2337.25 & 1 & 3143.00 \\
\hline Sarawak & 5 & 7811.00 & 3 & 2307.00 \\
\hline Sabah & 8 & 16248.00 & 8 & $24,526.00$ \\
\hline Total & $\mathbf{2 6}$ & $\mathbf{7 8 , 2 4 8 . 4 1}$ & $\mathbf{3 3}$ & $\mathbf{2 1 6 , 8 0 6 . 0 0}$ \\
\hline
\end{tabular}

Table 3: The number and production of feed mills in 2009 and 2013. operators and restaurants started again. Thus, the level of national farmed production has been inconsistent. However, with the high prices achievable for farmed prawns and with local product demand high and export potential existent, it still remains rather puzzling why, unlike its neighbor Thailand, the industry has failed to take off. Perhaps it is because Malaysia has a relatively small and more prosperous population than Thailand; that aquaculture is a 'last choice' career for most Malaysians and foreign farm workers have to be employed.

Under these conditions, existing farmers quickly become discouraged if production does not remain high; new investors cease operations once they encounter problems. The shortage of quality PL, together with the unavailability of many suitable ponds, continues to hinder expansion, despite government encouragement for the subsector. In an effort to stimulate the expansion of freshwater prawn farming in Malaysia, a seminar entitled 'Giant Malaysia Prawn 2008' was organized by the Malaysian Fisheries Society and other organizations, bringing experts from around the world to share their experiences.

During this meeting, genetic improvement programmes in China, India, Malaysia and the Philippines were described and a panel agreed that the way forward for the industry in Malaysia was through resolving the shortage of quality PL and genetic selection for disease resistance and improvements in growth rate and sex ratio. Giant freshwater prawn, $M$. rosenbergii is among commercial aquaculture species being given high priority not only by Department of Fisheries, Malaysia [15] as food and food products for consumption and export but also by research group [16-18] due to more and continuous development needed in various aspects of giant freshwater prawn aquaculture.

A number of factors favour the development of freshwater prawn farming in Malaysia:

1. Freshwater prawn farming does not require coastal sites, either for hatcheries or grow-out. Coastal hatcheries still exist but are not mandatory. Most hatcheries are now inland, using trucked seawater or brine, or artificial seawater, and often minimizing their use by recirculation systems.

2. With currently available technology, freshwater prawns can be reared in grow-out systems as intensively as marine shrimp. While this was often been regarded as a constraint by investors in the past, it may be an advantage for reasons of sustainability.

3. There is no shortage of egg-carrying females for hatcheries and, if the development of a captive brood stock is shown to be advisable for stock improvement, mating and spawning can easily be achieved in captivity.

4. Freshwater prawn farming is suitable for both large-scale and small-scale commercial rearing units. In addition, it is suitable for very small artisanal production units, which are often a target of government policies designed to favour riverine and other communities in poor regions.

5. Freshwater prawns are suitable candidates for inclusion in polyculture systems, and in integrated aquaculture agriculture. There is potential for freshwater prawns to occupy the bottom of countless hectares, providing an opportunity for fish farmers to increase production and profit with little extra investment and at no cost to the environment.

6. Export opportunities for freshwater prawns exist. Freshwater prawn, $M$. rosenbergii have long been exported globally are now 
a familiar sight in the supermarkets of Europe, USA and Japan. Bangladesh, India and Vietnam already export a significant proportion of their wild-caught and farmed prawns. Potential for expansion exists but producers will need to co-operate in collective marketing to exploit these opportunities.

Freshwater prawns are a product that is distinct from marine shrimp, with its own favourable culinary characteristics. The unique characteristics of the product require further image development. Further research and the more effective transfer of improved rearing and processing technology, is needed in order to exploit the opportunities for expansion in this sector of the aquaculture production.

\section{Conclusions and Recommendations}

Freshwater prawn farming plays an important role in the economy of Malaysia, contributing to increased food production and earning valuable foreign exchange, diversifying the economy and increased employment opportunities. Despite of several problems, the practice of prawn farming has offered opportunity to increase incomes for farmers and associated groups. The future for prawn farming is bright but requires dynamism to exploit fully. A range of public and private sector investments and initiatives are needed to realize the potential for growth and expanding economic output from this sector.

The realization of its potential must be aided by improvements in production technology and hatchery operation. Better brood stock for PL is required for successful operation of prawn hatcheries. A number of low-cost locally produced ingredients feed industries would help to increase farmer's profit margins and increase job opportunities. Therefore research would be required as quantitative and qualitative environmental impacts for sustainable prawn farming. In addition, research in areas such as seed and feed production may need to be given particular attention, considering existing technology, the transfer, adaption and development of new technology.

\section{Acknowledgement}

The authors are very grateful to the Department of Aquaculture, Faculty of Agriculture, University Putra Malaysia for the allocated budget and support with the technical equipment in this study. They acknowledge to the entire member at the Department of Fisheries, Ministry of Agriculture, Malaysia $[19,20]$ for providing the related documents in this study.

\section{References}

1. Jee KA (1998) Farming of giant freshwater prawn. In Aquaculture practices in Malaysia: Malaysian Fish, Society Occasional Publication.
2. Ling SW (1969) General biology and development of Macrobrachium rosenbergii. FAO, Fish Rep 57: 589-606.

3. Ling SW, Costello TJ (1979) The culture of freshwater prawns: A review. In Advances in Aquaculture. Papers presented at the FAO Technical Conference on Aquaculture, Fishing News Books, Blackwell Science, Oxford.

4. Anon (2009) Annual Fisheries Statistics, 2008, Department of Fisheries, Ministry of Agriculture, Malaysia, 176.

5. Anon (2010) Annual Fisheries Statistics, 2009, Department of Fisheries, Ministry of Agriculture, Malaysia, 188.

6. DOF (2011) Department of Fisheries, Malaysia.

7. FAO 2009. The state of world fisheries and aquaculture 2008. Rome (Italy): FAO Fisheries Department. $162 \mathrm{p}$.

8. DOF (2010) Department of fisheries, Malaysia.

9. FAO 2008. Fish stat Plus (v. 2.32) issued 11.03.2008. FAO, Rome.

10. New MB, Nair CM (2012) Global scale of freshwater prawn farming. Aquac Res 43: 960-969.

11. New MB (2010) History and global status of freshwater prawn farming. In Freshwater Prawns: Biology and Farming, Blackwell Science, UK.

12. Anon (2011) Annual Fisheries Statistics, 2010, Department of Fisheries, Ministry of Agriculture, Malaysia, 15

13. Sin OK (2009) Development of giant Malaysian prawn (Macrobrachium rosenbergii) culture in Malaysia. In Giant Malaysian Prawn, Malaysian Fisheries Society, Kuala Lampur, Malaysia.

14. New MB, Kutty MN (2010) Commercial freshwater prawn farming and enhancement around the world. In Freshwater Prawns: Biology and Farming Blackwell Science, UK

15. Anon (2012) Annual Fisheries Statistics, 2011, Department of Fisheries, Ministry of Agriculture, Malaysia, 20.

16. Banu MR, Christianus A, Islam MR, Ikhsan NFM, Rajaee AH (2014) Growth and survival of bilateral eyestalk ablated small male freshwater prawn Macrobrachium rosenbergii (DeMan). J Biol Sci 14: 527-531.

17. Banu MR, Christianus A, Ikhsan NFM, Rajaee AH (2015a) Effect of cold shock and hormone on growth and male morphotypes of freshwater prawn, Macrobrachium rosenbergii (de Man). Aquac Res.

18. Banu MR, Siraj SS, Christianus A, Ikhsan NFM, Rajaee AH (2015b) Genetic diversity among different morphotypes of the male freshwater prawn Macrobrachium rosenbergii (De Man). Aquac Rep 1: 15-19.

19. Anon (2013) Annual Fisheries Statistics, 2012, Department of Fisheries Ministry of Agriculture, Malaysia.

20. Anon (2014) Annual Fisheries Statistics, 2013, Department of Fisheries, Ministry of Agriculture, Malaysia. 